\title{
Artelogie
}

artelogie

Recherche sur les arts, le patrimoine et la littérature de l'Amérique latine

$7 \mid 2015$

Photographie contemporaine en Amérique latine

Fotografía e identidad. La revista "Mundo uruguayo" en la conformación de un nuevo imaginario nacional en el Uruguay del Centenario

\section{Magdalena Broquetas}

\section{(2) OpenEdition}

\section{Journals}

Edición electrónica

URL: https://journals.openedition.org/artelogie/1060

DOI: 10.4000/artelogie.1060

ISSN: 2115-6395

Editor

Association ESCAL

Referencia electrónica

Magdalena Broquetas, «Fotografía e identidad. La revista "Mundo uruguayo" en la conformación de un nuevo imaginario nacional en el Uruguay del Centenario», Artelogie [En línea], 7 | 2015, Publicado el 15 abril 2015, consultado el 11 abril 2022. URL: http://journals.openedition.org/artelogie/1060 ; DOl: https://doi.org/10.4000/artelogie.1060

Este documento fue generado automáticamente el 11 abril 2022.

Association ESCAL 


\title{
Fotografía e identidad. La revista
} "Mundo uruguayo" en la conformación de un nuevo imaginario nacional en el Uruguay
del Centenario

\author{
Magdalena Broquetas
}

1 En la tercera década del siglo XX Uruguay conmemoró su primer centenario como país independiente, lo cual se transformó en una ocasión propicia para consolidar socialmente un modelo de identidad que venía perfilándose desde los últimos años del siglo anterior. Tanto las conmemoraciones oficiales promovidas en este contexto, como el vasto corpus literario destinado a ensalzar la imagen del país entre potenciales turistas e inversores, han sido estudiadas como vehículos de difusión de este imaginario nacional que coincidió con la modernización económica y social del país.

2 Sin embargo, este fenómeno aún no ha sido examinado desde la prensa periódica, a pesar de las transformaciones experimentadas desde comienzos de siglo XX por diarios y revistas en lo que refiere a la inclusión de imágenes y su uso con fines políticos o propagandísticos. Partiendo del potencial alcance de las publicaciones periódicas en el período, en esta oportunidad se examinarán los contenidos gráficos de la revista Mundo Uruguayo procurando identificar el rol desempeñado por las imágenes en el marco del proceso de configuración de un nuevo modelo identitario.

\section{La fotografía llega a las revistas ilustradas y la prensa diaria}

3 Desde sus orígenes, la fotografía fue empleada para informar e ilustrar sobre acontecimientos diversos, aunque recién en los últimos años del siglo XIX, debido a las mejoras obtenidas en los procesos fotomecánicos, logró ser reproducida directamente 
en la prensa periódica. En la incorporación de la fotografía en el medio impreso incidieron varios factores, entre los que sobresalen las transformaciones en el concepto de "documento gráfico" y en el campo del periodismo, producto de los grandes cambios tecnológicos, económicos y socioculturales que trajo consigo la consolidación de la industrialización y la mundialización de la información. Este proceso tuvo sus características regionales y locales particulares, en las que incidieron factores económicos, estilos de trabajo periodístico y aspectos relativos a las mentalidades dominantes, tanto en los editores como en el público lector de los distintos países (Hassner, 1988 : 76-79 ; Sougez, 2007 : 183-214 ; Albert y Feyel, 1998 : 102-109).

4 En Uruguay las técnicas de grabado e impresión se perfeccionaron a partir de la década de 1880, aunque fue recién en el decenio siguiente cuando se produjeron cambios significativos en este terreno, abandonándose paulatinamente el procedimiento litográfico que hasta entonces había sido el más utilizado para estampar imágenes. Con el cambio de siglo la imagen fue ganando cada vez más importancia en las publicaciones periódicas, en la medida que los avances tecnológicos en los métodos de impresión posibilitaron cambios en los modos de presentación y en su interrelación con el texto escrito. Esta transformación alcanzó en los primeros años del siglo XX a las revistas y semanarios ilustrados y, recién hacia la segunda década a la prensa diaria (Broquetas, 2011: 144-174).

5 A comienzos de la década de 1890, La Ilustración Sud-Americana y la Revue ilustrée du Rio de la Plata se destacaron entre las publicaciones ilustradas dedicadas a un público selecto, tanto en Uruguay como en Argentina. A su vez, concebidas para un público más amplio, en simultáneo se distinguían por su moderno tratamiento gráfico publicaciones como Caras y Caretas (1890-1892 y 1894-1897), La Alborada (1896-1902) y Rojo y Blanco (1900-1903).

6 En el pasaje del siglo XIX al XX estas publicaciones utilizaron imágenes fotográficas con finalidades políticas (a modo de homenaje y promoción de determinadas figuras en la sección "álbum revolucionario"), inauguraron el espacio de "fotografía social" (compuesto por retratos de miembros de las clases altas) y reprodujeron vistas de la capital y el Interior del país. El abanico de temas que iban acompañados por imágenes fue ampliándose paulatinamente abarcando asuntos de actualidad y actividades de ocio y tiempo libre. En cuanto a la disposición en página, al menos hasta 1899, por norma general, las imágenes se ubicaban en el marco de artículos desligados de ellas, sin más referencias que un título o un escueto epígrafe. En este sentido, las fotografías eran empleadas a modo de "pretexto" o vía de entrada a un tema o acontecimiento específico, o bien para introducir datos biográficos del retratado.

7 En los primeros años del siglo XX las revistas ilustradas crecieron en volumen e incorporaron abundante material fotográfico, cuya presentación y lectura pasó a estar directamente vinculada a la información desarrollada en el texto escrito. Fotografías en diversos tamaños, formatos y composiciones pasaron a ocupar buena parte de las páginas de la revista, acompañadas por lo general de la referencia a su autor $\mathrm{y}$, en ocasiones, con comentarios y detalles sobre las circunstancias de toma. Reproduciendo una tendencia mundial, la influencia del cine repercutió en la adopción de estilos narrativos a través de la presentación de secuencias de imágenes, que buscaban informar y narrar de manera complementaria con el discurso escrito. Finalmente, la imagen única o aislada caía en desuso, optándose por las secuencias o las fotocomposiciones que, organizadas de manera cronológica o temática, traducían la 
sensación de transcurso o movimiento que caracterizará al foto-reportaje moderno. No obstante lo cual, a comienzos de siglo, los aspectos técnicos todavía imponían importantes restricciones tanto para la cobertura de acontecimientos como en el diseño gráfico de las publicaciones.

En lo que respecta a la prensa diaria, durante los últimos años del siglo XIX también incrementó el número de ilustraciones que acompañaba la información escrita, aunque continuó haciéndolo a través de grabados inspirados tanto en fotografías como en testimonios procedentes de testigos oculares o declaraciones policiales y judiciales, entre otros. Este tipo de ilustraciones empezó a ser utilizada con mayor frecuencia para la cobertura de crímenes y notas policiales. Entre 1904 y 1905 aparecieron las primeras fotografías, presentadas a modo de imágenes únicas o en composiciones de pares. Este tipo de reproducciones no desplazó inmediatamente a las ilustraciones surgidas de técnicas anteriores sino que se intercaló y compartió el espacio dedicado a la información gráfica, ocupando un lugar que recién será hegemónico en la década siguiente.

9 Con el cambio de siglo, dentro del género periodístico se produjeron modificaciones de estilo y lenguaje. La tradicional "crónica" de noticias pasó a convivir de manera incipiente con el "reportaje periodístico", caracterizado por un relato más activo y directo de los sucesos narrados. En este esquema la fotografía reforzaba el mensaje informativo, contribuyendo a esta modalidad de narración en tiempo real. Así, incluso antes de que pueda fijarse el predominio del reportaje periodístico en la prensa uruguaya, la "instantaneidad" en la toma y la "inmediatez" en el envío y reproducción de las imágenes pasaron a ser atributos explotados por quienes definían la línea editorial y valorados por el público lector. Al igual que ocurría con las revistas ilustradas, la prensa diaria consignaba explícitamente la presencia de "instantáneas" fotográficas entre sus páginas, sacando provecho del carácter reciente de sus contenidos. Para esto, desde luego, resultaron fundamentales los nuevos avances en los medios de comunicación y el perfeccionamiento en la transmisión de noticias y de imágenes.

10 La idea de primicia en la prensa diaria comprendió a las fotografías y, con frecuencia, se apoyó en ellas para reforzar la dimensión de lo novedoso. Gran parte de las imágenes fotográficas se presentaba acompañada de un pie explicativo en el que se enfatizaba su simultaneidad en relación a los sucesos registrados, así como el hecho de que no eran imágenes armadas, ni posadas, sino producto de la captura impulsiva del fotógrafo.

11 A su vez, fue ensanchándose el universo de temas y sujetos que merecían espacio en las páginas impresas. Las fotografías complementaban, enriquecían e ilustraban acontecimientos políticos cada vez con mayor frecuencia. La inclusión sistemática de fotografías de prensa de "personalidades" que ocupaban altos cargos públicos constituye un buen ejemplo de este fenómeno. Los lectores recibían con regularidad información gráfica sobre jerarcas nacionales y municipales y, por este medio, también era factible acceder a la imagen y actividad pública de visitas de delegaciones diplomáticas y extranjeros ilustres. Por otra parte, tópicos novedosos, como el ocio, la cultura o el campo del deporte, comenzaron a ocupar cada vez más espacio en la prensa periódica a través de las fotografías.

12 También, incluso cuando no alcanzaban a configurar foto-reportajes en el sentido moderno del término, en el pasaje hacia la segunda década del siglo XX puede reconocerse un incipiente uso de la fotografía al servicio de la denuncia social. 

del uso de la imagen en la prensa, los diarios fueron incorporando sus propios fotógrafos, como la dupla compuesta por Isidoro Damonte y Marcelino Buscasso, quienes nutrieron la sección “Notas Gráficas” del diario El Día desde 1907. se dieron en la prensa uruguaya hacia fines de la segunda década del siglo xx. Ya en 1915, el diario El Plata presentó algunas novedades en el uso y los modos de presentación de las imágenes fotográficas, aunque las innovaciones más elocuentes en este sentido se dieron con la aparición de La Mañana y El País en 1917 y 1918. Estas transformaciones acompasaron cambios en el uso de las imágenes con fines informativos y de formación de opinión.

Durante la segunda década del siglo XX se produjeron cambios significativos en el diseño y en la presentación gráfica de diarios y periódicos.

\section{El Siglo llustrado, Montevideo, 16 de abril de 1916}

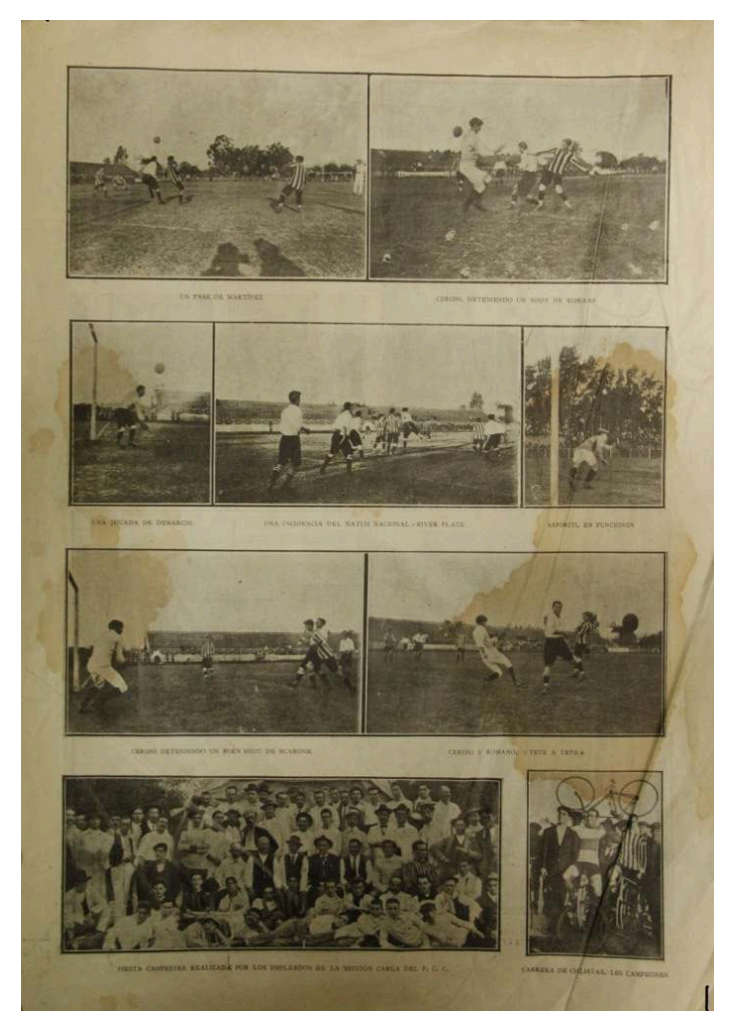

\section{El Uruguay del Centenario}

En los años veinte del siglo pasado el Uruguay festejó el centenario de su independencia nacional en dos oportunidades, en 1925 y 1930. ${ }^{1}$ Los debates suscitados en torno a ambas fechas y el programa de festejos definido desde el gobierno representan un ejemplo de tradición inventada, propio de los procesos modernos de construcción nacional (Hobsbawm, Ranger: 2002). En este marco se consolidó lo que el historiador Carlos Demasi ha llamado "un nuevo relato de los orígenes", íntimamente vinculado con la situación institucional derivada de la reforma constitucional que entró en 
vigencia en $1919^{2}$ y en la que el Parlamento pasó a ocupar lugar de privilegio en la vida pública (Demasi, 2004: 67-68 y Rodríguez Ayçaguer, 2007: 51-84).

La polémica sobre el origen de la nación se desarrolló en las cámaras legislativas, cuyos miembros, ante la inminencia de los festejos, se sintieron conminados a zanjar la nunca resuelta fecha de la independencia de Uruguay. En el transcurso del año 1923 fueron discutidos varios proyectos sin arribar a un veredicto concluyente, lo cual derivó en la habilitación de un festejo conciliador que contemplaba ambas fechas. Como ha señalado Gerardo Caetano, aunque tampoco en esta oportunidad se generó consenso acerca un "momento fundante de la nación", se produjo una "radicalización en la 'obsesión' por el pasado colectivo como hipotético sustento de la nación". En este marco "el mito de un 'pasado de oro' podía sustituir al mito de los 'orígenes' como cimiento consistente y perdurable de la nacionalidad" (Caetano, 1990: 25). Asimismo, se enfatizó la idea de estar viviendo un tiempo nuevo y promisorio. Por estos motivos es posible afirmar que, durante las tres primeras décadas del siglo XX, la sociedad uruguaya acabó por consolidar un nuevo modelo de identidad nacional, surgido varias décadas atrás.

Acorde con las transformaciones políticas, sociales, económicas y culturales ocurridas a lo largo de estos treinta años, la nueva matriz identitaria presentó los rasgos de un "modelo integrador de base uniformizante". En esta dirección el discurso oficial privilegió la idea de una sociedad cosmopolita conformada por un "crisol de identidades" que eran asimiladas con éxito a través de la política (estatal y partidaria) y la educación pública y destacó la "excepcionalidad" del país en aspectos tan diversos como su continuidad democrática, sus bellezas naturales o sus éxitos deportivos (Caetano, 1996: 84-86). En suma, Uruguay era presentado como un país "excepcional" en el mundo, pero fundamentalmente en relación a los demás países de América Latina-, que había modernizado su sistema de partidos, establecido garantías para el sufragio que se hacía extensivo a todos los varones y consolidado un proyecto de desarrollo nacional a través de la acción del Estado en áreas consideradas prioritarias y la construcción de obras públicas.

\section{El papel de las imágenes en la reconfiguración "identitaria”}

Este culto a la excepcionalidad del Uruguay quedó reflejado en la agenda conmemorativa del Centenario y en diversos artefactos materiales concebidos en el marco de los festejos. Entre estos últimos figuran algunos libros ilustrados editados o auspiciados por el Estado, entre 1910 y 1925, con el objetivo de "poner en evidencia, ante propios y extraños, los progresos realizados por el país, en las diversas esferas de su actividad orgánica". ${ }^{3}$ Este corpus que conformó la literatura del Centenario circuló dentro y fuera del país, reproduciendo la caracterización del Uruguay como "país modelo". En él las imágenes desempeñaron un papel protagónico, reforzando el contenido de los textos y ratificando este mensaje celebratorio. 


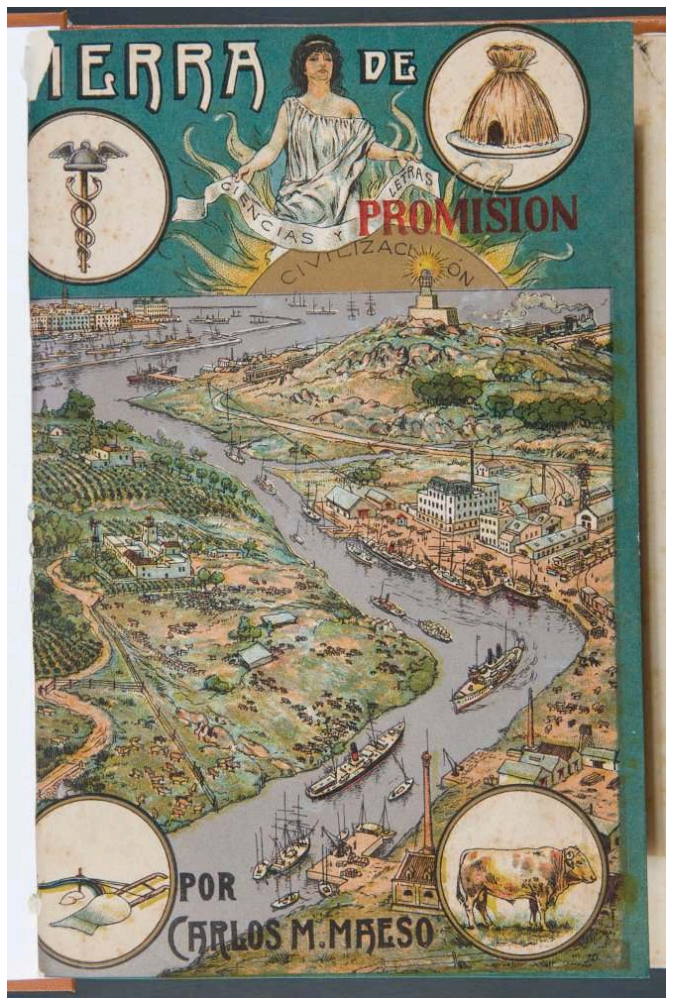

Montevideo, Tipografía de la Escuela Nacional de Artes y Oficios, portada.

En su estudio sobre la imagen de Uruguay proyectada dentro y fuera de fronteras, Clara Von Sanden advierte que "además de fomentar el turismo interno, estas obras pretendían animar al público radicado en Uruguay a valorar las bellezas y progresos del país. En este marco, las imágenes le otorgaban credibilidad, servían de elementos de prueba del discurso que explicaba y celebraba al Uruguay como un buen lugar para vivir" (Von Sanden, $2011: 220$ ). Con ellas se quería ilustrar el proceso de modernización económica y social del país, por lo que abundaban las representaciones visuales de establecimientos agropecuarios, industriales y comerciales. A su vez, tanto las imágenes como el texto fortalecían la idea de un país joven y sin elementos que pudieran resultar exóticos para el europeo.

En esta dirección fueron seleccionadas fotografías de paisajes agrestes que presentaban similitudes con los europeos (como el Salto del Penitente o la Sierra de las Ánimas). Abundaban las fotografías de arquitectura que mostraban la extendida presencia de edificios modernos -muchos de ellos de estilo art nouveau- y la inexistencia de huellas del pasado colonial, así como las elegantes fachadas de edificios estatales o de instituciones privadas, en su mayoría ubicados en la zona céntrica de la capital o en la costa. El progreso arquitectónico también era certificado mediante la inclusión de croquis, planos y bocetos que daban cuenta del crecimiento continuo de determinadas áreas de la ciudad.

21 Asimismo, la idea de un Estado sólido y protector (lo cual acompasaba la estrategia política del reformismo ${ }^{4}$ ) quedaba ratificada a través de imágenes que mostraban obras de infraestructura y modernos medios de transporte y de edificios dedicados a la enseñanza, entre los que sobresalían suntuosos edificios de escuelas primarias, dependencias universitarias y escuelas técnicas. Estos últimos abonaban la imagen de 
un Estado que expandía la educación hacia vastos sectores sociales, al tiempo que invertía en ella y complementaban el registro de instituciones hospitalarias y de vigilancia y control social, como la cárcel penitenciaria de Montevideo o el Lazareto de Isla de Flores

La "literatura del Centenario" incluyó fotografías de comisarías y cárceles con el objetivo de reproducir la imagen de un Estado moderno, que había logrado controla exitosamente el orden interno y en el que ya no tenían lugar levantamientos armados.

Cárcel Penitenciaria de Punta Carretas, Libro del Centenario del Uruguay, 1925

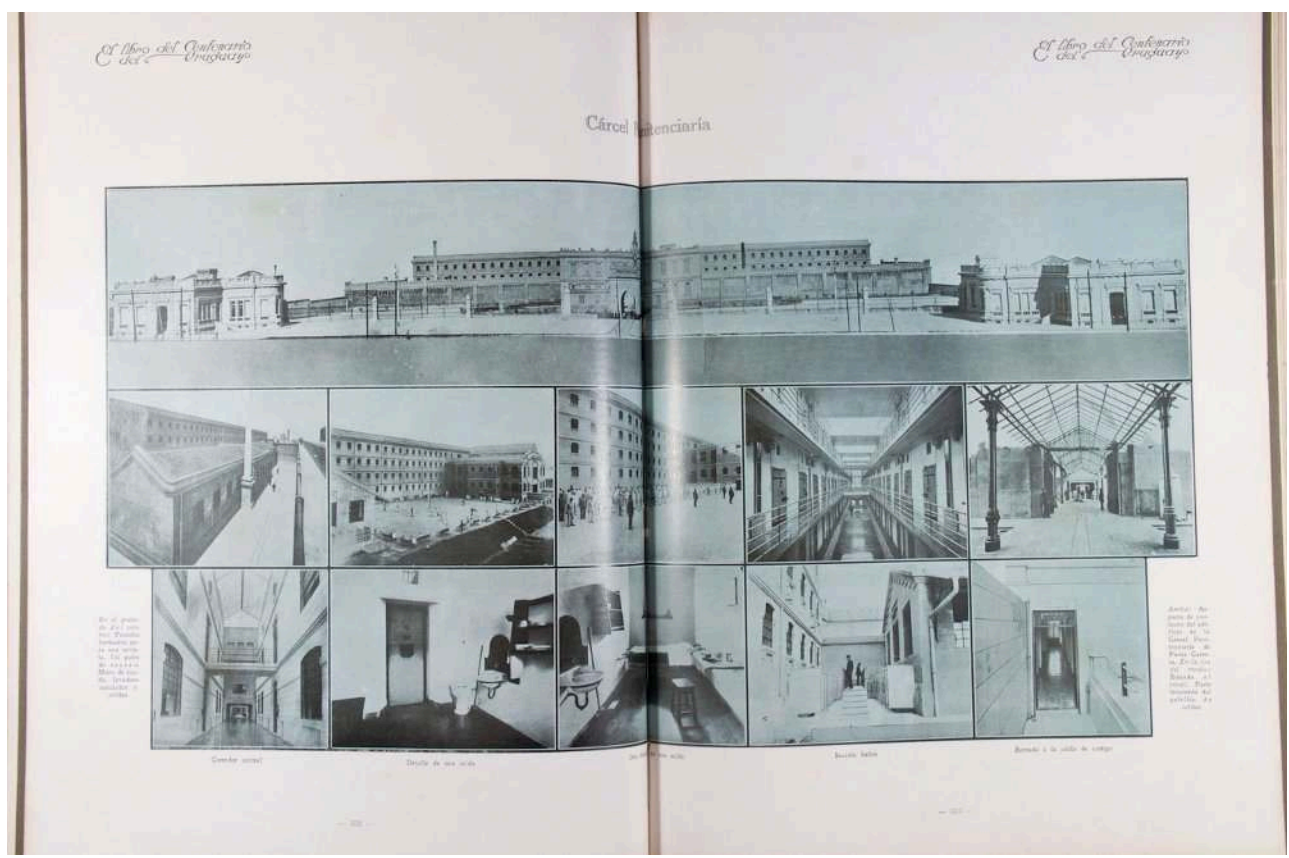

Montevideo, Agencia de Publicidad Capurro \& Co., pp. 352-353.

En paralelo a la exaltación de estos aspectos históricos, demográficos, sociales y culturales, el discurso oficial ocultó aquellos que resultaban disfuncionales al modelo identitario que se consolidaba. Así, como han señalado Ana Frega y Ariadna Islas, en el relato histórico que construyó una "gesta fundacional" se omitían "los lazos del país con la región y el componente de violencia étnica y civil que había caracterizado la formación del Uruguay" (Frega, Islas, 2007: 361). Esta ausencia de conflicto social y político encontraba su correlato en el discurso visual de la literatura del Centenario que evitó cualquier referencia a la población rural o indígena, excepto en la versión épica de la narrativa y en los monumentos públicos que difundieron una visión idealizada y descontextualizada de ambos actores sociales.

\section{El predominio de un relato visual en Mundo Uruguayo}

Inspirada en Mundo Argentino -una publicación de la Editorial Haynes que circulaba desde 1911, a la que emuló en diseño y contenidos periodísticos-, la revista Mundo Uruguayo publicó su primer número en el año 1919 y continuó saliendo de forma ininterrumpida hasta 1967 (Álvarez Ferretjans, 2008 : 470-471). En materia visual Mundo Uruguayo marcó un punto de inflexión en relación a sus antecesoras revistas ilustradas. 
Esto se debió básicamente a dos aspectos: su atractiva propuesta gráfica, caracterizada por el uso de numerosas imágenes que en ocasiones llegaban incluso a suplir a los textos escritos, y la adopción de un lenguaje periodístico de estilo sencillo, accesible para un público amplio que en gran medida inauguraba un nuevo universo de lectores. Por otra parte, aunque faltan estudios específicos sobre múltiples aspectos que hacen a esta publicación, no parece arriesgado aventurar que, a diferencia de las revistas ilustradas de principios de siglo, cuya circulación se restringía a un público mucho más acotado, Mundo Uruguayo fue una revista de consumo masivo que atrajo a un amplio espectro de lectores. Una década después de su aparición pública, en agosto de 1930, los editores declaraban un tiraje de cincuenta mil quinientos ejemplares, lo cual representaba una cifra muy alta para Uruguay..$^{5}$

Al comenzar la década de 1920 la publicación incluía fotografías que cubrían aspectos de la vida cultural y social, correspondientes en su mayoría a escenarios de capital y a actividades de las clases altas. A su vez figuraban las siguientes secciones organizadas exclusivamente a partir de fotografías: "Instantáneas" (compuesta por fotografías ocasionales tomadas a modo de "captura" callejera de figuras relevantes en el mundo de la política o de los negocios); "Notas de actualidad" (apartado que cubría un amplio espectro que podía comprender desde aspectos urbanísticos hasta actividad cultural, también presente en "Notas diversas"); "Del ambiente artístico"; "Notas deportivas", "Actualidad extranjera" y "Fiestas y banquetes".

Desde sus inicios también fue frecuente la realización de concursos fotográficos sobre temas diversos. Entre el 9 de junio y el 15 de setiembre de 1921 la revista organizó un "concurso de carátulas" para el que se convocó a "todos los fotógrafos y aficionados del país" a expresarse sobre "asuntos del ambiente, paisajes, escenas campestres, notas sociales, bellezas femeninas, costumbres, cuadros urbanos y notas de actualidad". ${ }^{6}$ La fotografía ganadora obtendría un premio en dinero, aunque se especificaba la voluntad de publicar todos los trabajos recibidos, siempre y cuando se ajustaran a los criterios editoriales y de contenido establecidos por la redacción. 


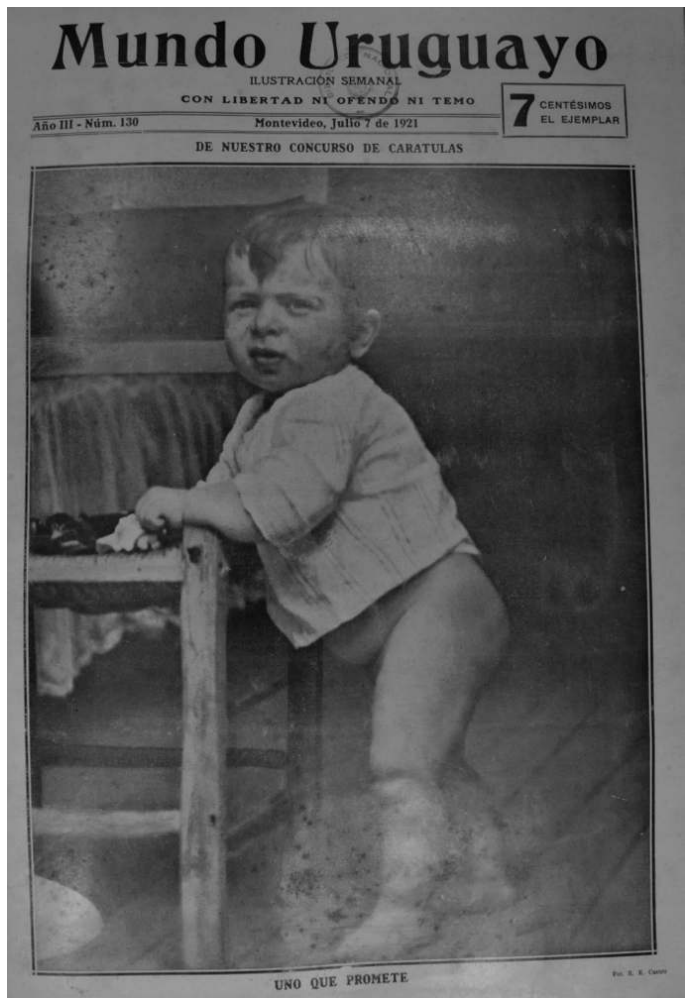

Foto : R. E. Castro

27 En este período el trabajo de varios fotógrafos alcanzó una amplia difusión a través de las portadas de la revista que, de acuerdo a lo anticipado, publicó aquellas que se ajustaban al carácter artístico y pintoresco siguiendo una línea predominante en tendencias mundiales y reproducidas por el fotoclubismo local. En agosto de 1921 la revista lanzó un "gran certamen de belleza infantil", para lo cual se solicitó el envío de retratos individuales y de busto y en 1922, junto al estudio Fotofaig, organizó un concurso de "disfraces infantiles". ${ }^{7}$ Durante los meses siguientes, los envíos a ambos certámenes nutrieron las páginas de numerosas entregas de Mundo Uruguayo.

Con frecuencia las imágenes también fueron utilizadas para acercar al público uruguayo lugares y acontecimientos de todo el mundo (esto fue usual en la sección "Actualidad extranjera"), deviniendo, en combinación con los textos, en testimonios privilegiados sobre la miradas hacia los "otros". Estos acercamientos reproducían en gran medida los prejuicios predominantes en la época, tal como queda de manifiesto en una cobertura gráfica del mes de mayo de 1925 sobre la apariencia física de los habitantes del Congo. Entre otros, el pie que acompañaba al retrato de un lugareño indicando que "en el Camerón, el supremo chic consiste en depilarse las pestañas y cejas, 'barrete' en la nariz, una sola carabana [sic], y bellos adornos en la piel" traduce una curiosidad antropológica, no exenta de frivolidad, que se presenta como una constante en los acercamientos hacia culturas no occidentales. ${ }^{8}$

La fotografía actuó en esta publicación como un importante canal de difusión de piezas y sitios arqueológicos de lugares lejanos y sirvió para divulgar obras pictóricas de artistas nacionales y extranjeros, potenciando su difusión entre un público más amplio que el que accedía a museos u otras instituciones culturales. A su vez, ya en sus primeros años se reconocen dos marcadas tendencias que serán una constante de la 
publicación durante toda la década: la adhesión a un imaginario cosmopolita reflejada en la conmemoración de fechas emblemáticas de otros países (independencia estadounidense o 14 de Julio francés) y la contribución a la formación de una conciencia histórica nacional. Esta tendencia puede reconocerse en la profusa cobertura gráfica de actos cívicos, aunque también está presente en diversas fotocomposiciones (que intercalaban grabados con fotografías) organizadas a modo de retrospectivas históricas sobre temas específicos. ${ }^{9}$

\section{Mundo uruguayo en la conmemoración del Centenario}

En 1925 la revista formó parte de los festejos del centenario de la independencia nacional, contribuyendo a la formación de la memoria histórica y de una conciencia nacional inscripta en la línea oficial ya descripta. La portada del número correspondiente al feriado del 19 de abril contuvo un texto sobre "el primer hecho glorioso de nuestra epopeya libertadora del año 1825", acompañado del retrato de Juan Antonio Lavalleja y el paradigmático óleo de Juan Manuel Blanes sobre el desembarco de los Treinta y Tres Orientales. ${ }^{10} \mathrm{En}$ su interior una composición fotográfica a doble página documentaba los festejos de "la histórica playa de la Agraciada".

31 Meses más tarde, antes y después de la conmemoración del 25 de agosto, Mundo Uruguayo centró gran parte de su cobertura gráfica sobre este tema. En el número correspondiente al 20 de agosto publicó en portada una fotografía que testimoniaba la celebración de esa misma fecha treinta años antes en una de las principales plazas céntricas adornadas con elementos de arquitectura efímera. ${ }^{11}$

En 1925 la revista Mundo Uruguayo formó parte de los festejos del centenario de la independencia nacional, contribuyendo a la formación de la memoria histórica y de una conciencia nacional. 


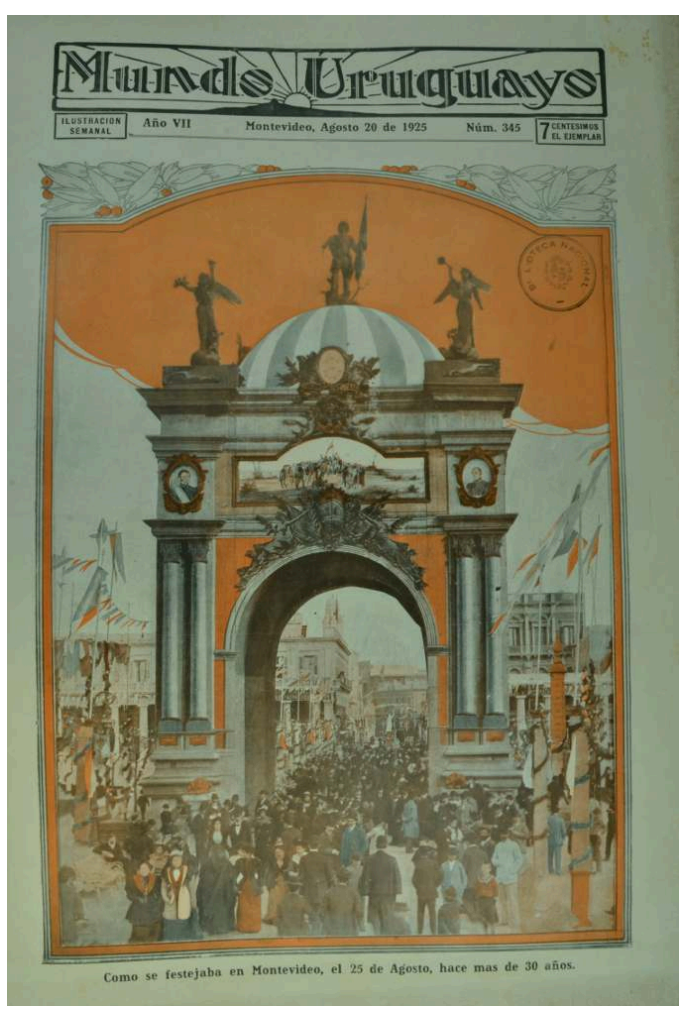

El mismo número incluía amplias coberturas ilustradas sobre los "miembros de la Asamblea Constituyente que labraron el acta de la Declaratoria de la Independencia Nacional" (reproducción de grabados con sus retratos), el "monumento a la Independencia erigido en la Plaza de la Asamblea, en la Florida" y el nuevo "palacio legislativo" (destinado a las cámaras parlamentarias), presentado como un "verdadero exponente de la riqueza nacional". La voluntad por forjar una conciencia histórica y el paralelismo entre pasado glorioso y presente promisorio son reconocibles nuevamente en el interior de este número a través de dos imágenes ubicadas bajo el título "recuerdos de otros tiempos". A su vez, en los primeros números del mes de setiembre se publicaron abundantes imágenes sobre los festejos cívicos en distintas partes del país. Sin embargo, la euforia conmemorativa de Mundo Uruguayo se produjo cinco años más tarde, al celebrarse el aniversario de la primera constitución nacional.

En la entrega correspondiente al 26 de junio de 1930 se anunciaba la preparación de un número especial, con ochenta páginas ilustradas y doscientas de texto, sobre "Montevideo a través del tiempo". Se trataba de un "homenaje al Centenario Nacional" que finalmente fue publicado el 18 de julio con una portada que reproducía la alegoría de Juan Manuel Blanes sobre el nacimiento de la patria. ${ }^{12}$ Distribuidas a lo largo de todo el número, las imágenes contribuían a ratificar las principales ideas-fuerza del relato hegemónico acerca del país y sus habitantes, luego de cien años de vida independiente. Numerosas imágenes abonaban la percepción en torno a la solidez de los gobernantes y las instituciones republicanas: retratos que conformaban una genealogía de los distintos mandatarios desde el primer presidente constitucional, el presidente de ese momento junto a sus ministros y los miembros del Consejo Nacional de Administración, los siete miembros del gobierno municipal de la capital, los jefes de las distintas Direcciones del Consejo Departamental de Montevideo y los presidentes de ambas 
cámaras legislativas. Los rostros del elenco de gobierno alternaban con los de las principales instituciones, entre las que figuraban la casa de gobierno y el Cabildo (para la fecha sede del Consejo Nacional de Administración), la sede del Poder Judicial y el nuevo "palacio de las leyes", cuya construcción se hallaba casi finalizada. El pie que acompañaba al retrato del arquitecto Gaetano Moretti, autor del proyecto que había dado origen al suntuoso edificio, subrayando el "orgullo" que inspiraba la nueva sede, condensaba el tono característico de esta publicación.

Mundo Uruguayo, 26 de junio de 1930

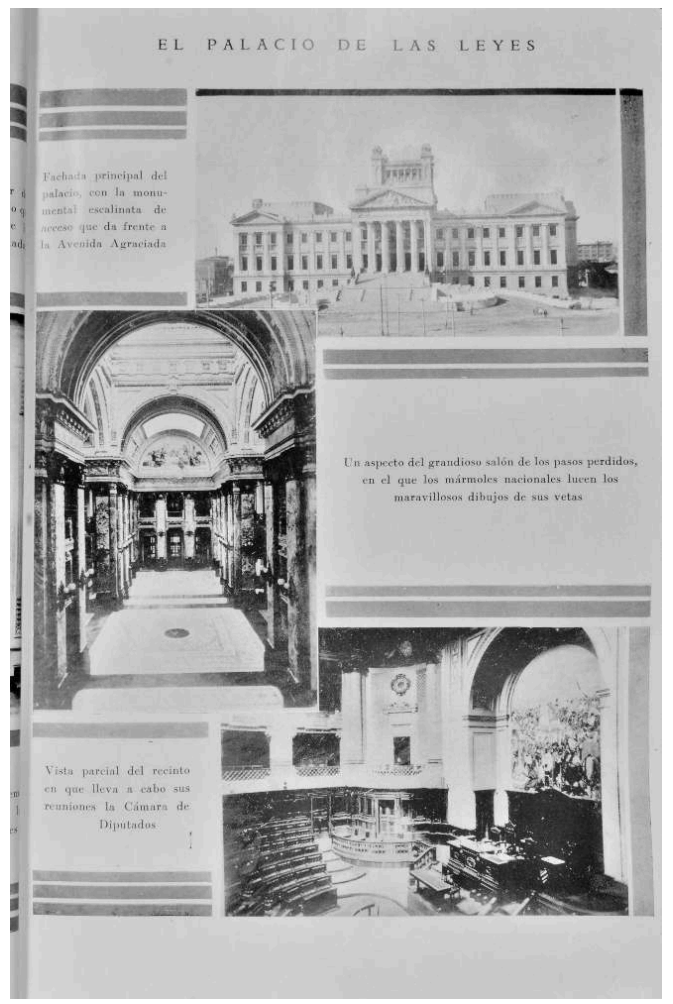

Otro grupo de imágenes documentaba y al mismo tiempo reforzaba la sensación de un país que atravesaba un crecimiento urbanístico y edilicio exponencial. Bajo esta categoría pueden agruparse las imágenes que documentan "los monumentos de la ciudad", las transformaciones en el Puerto de Montevideo (mediante el empleo de fotos de archivo se exhibía el "antes" y el "después" de los cambios de infraestructura), la instalación de pavimentos en las principales calles montevideanas y el "progreso en el Interior del país". El efecto de optimismo y pujanza que traducen estas fotografías si se las observa en conjunto, se proyecta hacia el futuro a través de la inclusión de proyectos de transformación y crecimiento de la ciudad. Finalmente, precedidas por un encabezado titulado "Montevideo desde el cielo", cuatro fotografías aéreas de gran tamaño corroboran la expansión y el desarrollo edilicio de la ciudad en la zona costera. Imágenes de las fachadas e interiores de grandes comercios también fueron incluidas como testimonio del crecimiento económico del país. 
Mundo Uruguayo, 26 de junio de 1930

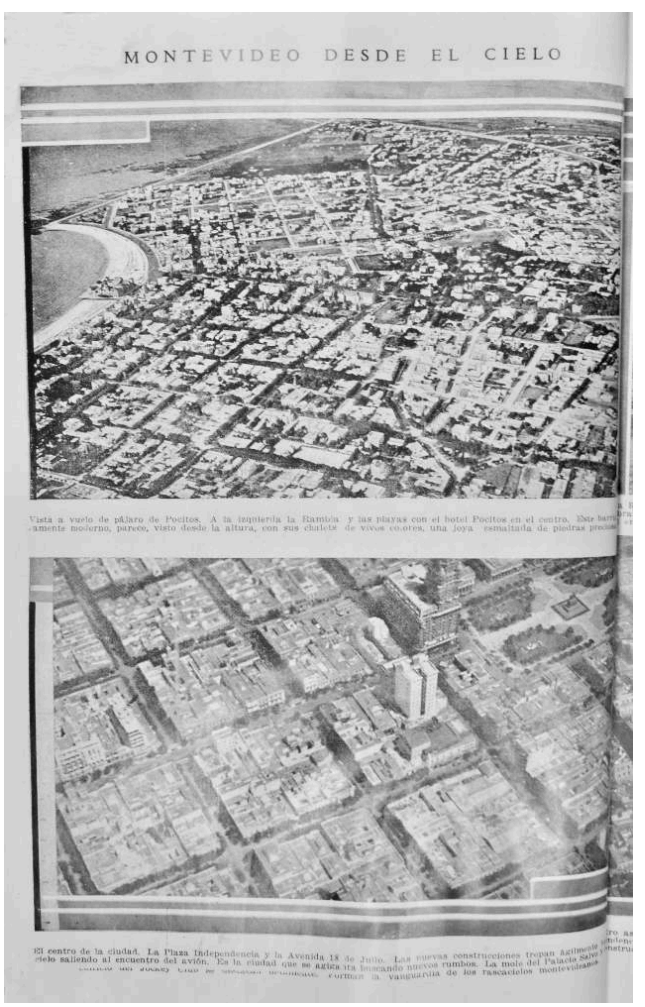

Mundo Uruguayo, 26 de junio de 1930

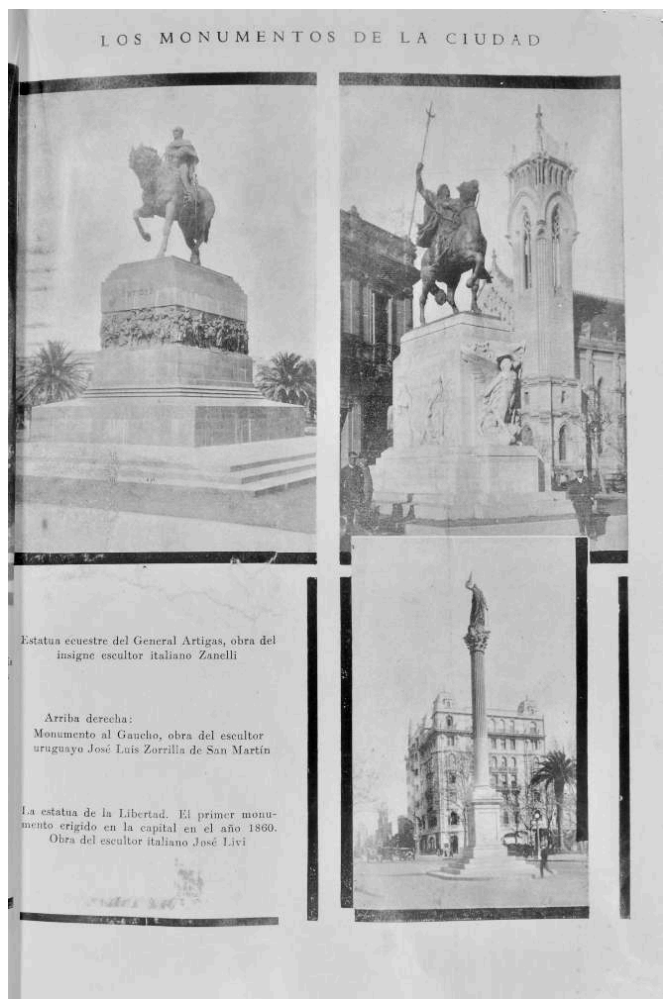

Las imágenes corroboraban la idea de una ciudad capital en pleno empuje de crecimiento edicilio y urbanísitico. 

"progreso" y "civilización", las imágenes publicadas en ocasión del Centenario buscaron reflejar la idea de un pueblo culto (europeizado, ajeno a la herencia cultural local) y tolerante. Entre los íconos representativos de ese matiz civilizatorio figuraba la Biblioteca Nacional, a la que se le dedicaron dos páginas conteniendo imágenes de su director y su fundador y de la sala de lectura. Según resaltaba el acápite de esta nota, se trataba de "una institución que honra[ba] al país y a la cultura política". Siguiendo esta misma línea se exaltaba la laicidad de la educación uruguaya y la figura de su "reformador" decimonónico, aunque esto no impedía elogiar al Arzobispo Francisco Aragone, principal figura de la Iglesia Católica del Uruguay. La publicación también incluía retratos de "figuras descollantes de la literatura uruguaya" y la "dramaturgia nacional".

Otro conjunto de fotografías estaba dedicado a la exaltación de las victorias futbolísticas de Uruguay estableciendo un paralelismo entre los éxitos pasados y el campeonato mundial que un mes más tarde tendría sede en Uruguay y se desarrollaría en un nuevo estadio, que también será presentado como factor de orgullo nacional. El retrato del seleccionado uruguayo, publicado a doble página como parte de un montaje en el que figuraba una locomotora, estaba acompañado por la siguiente inscripción: "Fabrica Nacional de máquinas olímpicas. A.[sociación] U.[ruguaya] de F.[útbol] [...] No hay dos sin tres ... 1924 ... 1928 ... 1930 ?"

Mundo Uruguayo, 26 de junio de 1930

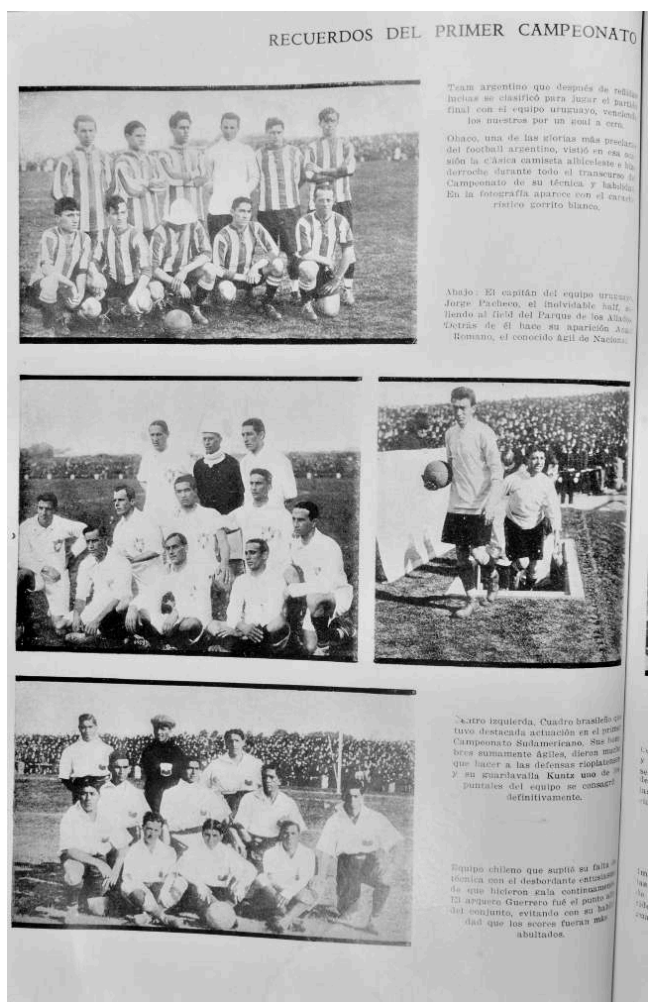




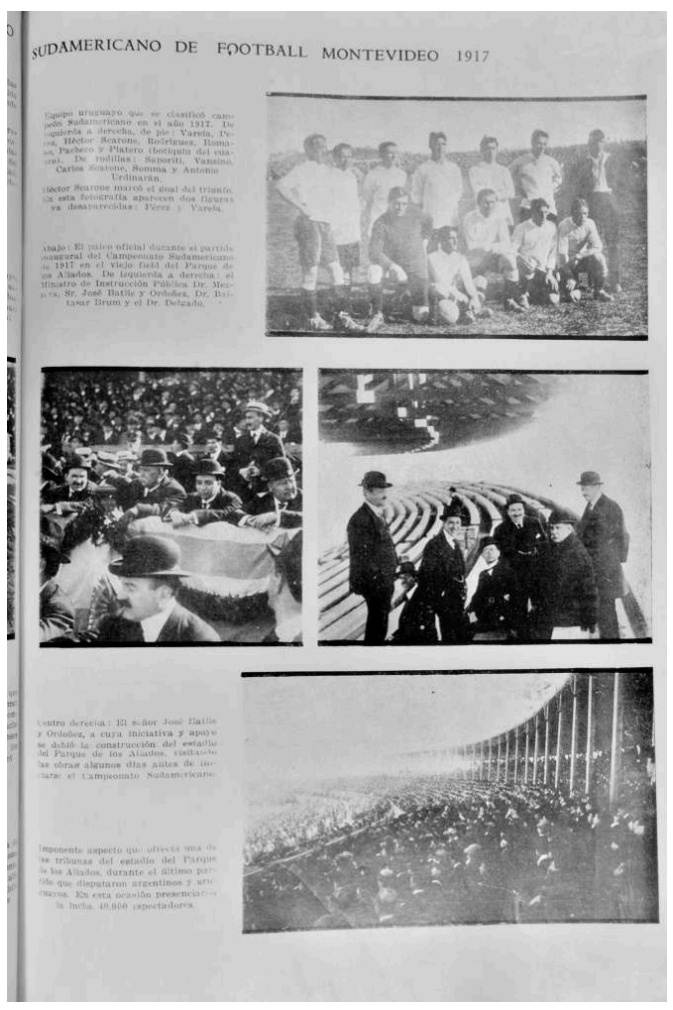

Las victorias futbolísticas fueron exhibidas como factor de orgullo nacional.

En este número especial también se evocaron hechos históricos a través de la reproducción de óleos de Juan Manuel Blanes y se exhibieron sitios arqueológicos como la fortaleza de Santa Teresa en el Departamento de Rocha, presentada como baluarte de la época colonial con potencial valor turístico. Precisamente el nexo con el pasado colonial e hispánico se limitaba a la recuperación de lugares arqueológicos, mientras la ciudad que crecía se presentaba "moderna" y afrancesada en su arquitectura y tendencias culturales.

Finalmente la publicación contaba con varios retratos que reproducían la lógica del "ayer" y "hoy", estableciendo una línea de continuidad entre las "damas de antaño" y las "niñas de nuestra sociedad", las "madres uruguayas" y "la nueva generación uruguaya", representados en todos los casos por las familias de clase alta que solían ocupar el espacio de "sociales".

\section{Reflexiones finales}

A través de los ejemplos citados ha quedado de manifiesto la participación de la revista Mundo Uruguayo en la difusión de los mismos valores transmitidos por el discurso oficial en torno a qué significaba "ser uruguayo". La construcción de este nuevo imaginario supuso una revisión del pasado histórico -inventando tradiciones y omitiendo episodios de violencia política y social que habían jalonado el acontecer histórico de la región- y una cuidadosa selección de rasgos identitarios que resaltaron la imagen de una sociedad homogénea, pacifista, cosmopolita, de origen y hábitos europeos, en la que se encontraba fuertemente arraigadas las prácticas democráticas. 

construcción de monumentos y obras públicas y quedaron plasmados en la "literatura del Centenario". Sin embargo, hasta el momento los estudios históricos sobre los años veinte y la conmemoración del centenario no han tenido en cuenta la difusión de este mensaje a través de canales con una efectiva capacidad de llegada a las capas medias de la sociedad. En este artículo se ha planteado que, nutriéndose de los avances técnicos y las novedades transitadas por las revistas ilustradas y la prensa en las dos década anteriores, una revista como Mundo Uruguayo, con tirajes elevados y recepcionada por un público masivo, atraído fundamentalmente por el componente gráfico, no sólo ilustró y documentó, sino que a través de las secuencias de imágenes y fotocomposiciones que integraron el número especial del Centenario, contribuyó activamente en la formación de opinión y en la construcción de una "comunidad imaginada" surgida como resultado de un pasado dorado e inmersa en un presente excepcional.

En otro orden, la gran cantidad de imágenes concebidas para documentar diversos aspectos del acontecer abre una brecha para futuras investigaciones desde otro ángulo. Tomando en cuenta la especificidad de las fuentes fotográficas, los contenidos gráficos de Mundo Uruguayo, al igual que la literatura del Centenario, son pasibles de ser leídos a contrapelo de su sentido original. Así, de la lectura entre líneas que los historiadores realicemos de las imágenes apuntando a los detalles y presencias que pueden parecer insignificantes para un observador común o hayan escapado a la voluntad de sus creadores, surgirán nuevos indicios que contribuirán a profundizar el conocimiento de sectores sub-representados en la iconografía de las primeras décadas del siglo xx, como los sectores populares o el numeroso colectivo de mujeres que no integraba las clases altas y permanecía al margen de la sección de "fotografía social".

\section{BIBLIOGRAFÍA}

ALBERT Pierre, FEYEL Gilles, "Photography and the media", in A new history of photography, Frizot, Michel (ed.), Köln, Könemann, 1998.

ÁLVAREZ FERRETJANS Daniel, Desde la estrella del Sur a Internet. Historia de la prensa gráfica en el Uruguay, Montevideo, Fin de siglo, 2008.

Artelogie, 7 | 2015 
BROQUETAS Magdalena, Fotografía e información. Las imágenes como modelo, ilustración y documento. 1840-1919, in Fotografía en Uruguay. Historia y usos sociales: 1840-1930, Broquetas, M. (coord.), Montevideo, Ediciones CdF, 2011, p. 144-175.

CAETANO Gerardo, "Notas para una revisión histórica sobre la cuestión nacional en el Uruguay", in Cultura(s) y nación en el Uruguay de fin de siglo, Hugo ACHUGAR, Montevideo, Logos-FESUR, 1990.

CAETANO Gerardo, "Identidad nacional e imaginario colectivo en Uruguay. La síntesis perdurable del Centenario", in Identidad uruguaya: ¿mito, crisis o afirmación?, Varios Autores, Montevideo, Ediciones Trilce, 1992.

DEMASI Carlos, La lucha por el pasado. Historia y nación en el Uruguay (1920-1930), Montevideo, Ediciones Trilce, 2004.

FREGA Ana, ISLAS Ariadna, “Identidades uruguayas: del mito de la sociedad homogénea al reconocimiento de la pluralidad", in Historia del Uruguay en el siglo XX (1890-2005), AAVV, Montevideo, Ediciones de la Banda Oriental, 2007, p. 359-392.

HASSNER Rune, “La fotografía y la prensa”, en : Lemagny, Jean-Claude, Roullié, André (dirs.), Historia de la fotografía, Arcor, Barcelona, 1988.

HOBSBAWM Eric, RANGER Terence (eds.), La invención de la tradición, Barcelona, Editorial Crítica, 2002. RODRíGUEZ Ayçaguer ANA María, “La República del compromiso. 1919-1931”, in Historia del Uruguay en el siglo XX (1890-2005), AAVV, Montevideo, Ediciones de la Banda Oriental, 2007, p. 51-84.

SOUGEZ Marie-Loup, "La fotografía en el medio impreso”, in Historia general de la Fotografía, Sougez, M.L., Madrid, Ediciones Cátedra, 2007, p. 183-214.

VON SANDEN Clara, "La imagen del Uruguay dentro y fuera de fronteras. La fotografía entre la identidad nacional y la propaganda del país en el exterior. 1866-1930", in Fotografía en Uruguay. Historia, y usos sociales: 1840-1930, M. BROQUETAS (coord.), Ediciones CdF, 2011, Montevideo, pp. 200-232.

\section{NOTAS}

1. Procurando zanjar un debate permeado por las diferencias partidarias y los usos políticos de la historia, Uruguay festejó los cien años de su vida independiente en dos fechas asociadas a la fundación del Estado: el 25 de agosto de 1925 (declaratoria de la independencia nacional) y el 18 de julio de 1930 (jura de la primera carta constitucional).

2. La nueva constitución fue plebiscitada el 25 de noviembre de 1917 y entró en vigencia el $1^{\circ}$ de marzo de 1919. Entre los cambios fundamentales con respecto a su antecesora, vigente desde 1830, figuran la laicización del Estado, la concesión del derecho a voto a todos los varones de 18 años (con la excepción de los soldados) y la implantación de un Poder Ejecutivo colegiado que a su vez se estructuraría de forma bicéfala en dos órganos : el Presidentes de la República y el Consejo Nacional de Administración.

3. El libro del Centenario del Uruguay, Montevideo, Agencia 'Publicidad' Capurro \& Co., 1925, p. 5.

4. El término batllismo o reformismo (como se lo denominó en la época), alude a una corriente dentro del Partido Colorado inspirada en las ideas de José Batlle y Ordónez, líder de este movimiento político y presidente del Uruguay en los períodos comprendidos entre 1903 y 1907 y 1911 y 1915. El batllismo impulsó una fuerte presencia del Estado en todos los aspectos que hacían al desarrollo del país, propiciando en consecuencia profundas reformas en los planos social, económico, cultural, religioso y moral. 
5. "Los enormes tirajes de Mundo Uruguayo", Mundo Uruguayo, 14 de agosto de 1930.

6. “Concurso de carátulas para Mundo Uruguayo", Mundo Uruguayo, 7 de julio de 1921.

7. "Mundo Uruguayo y La Razón por la estética y la salud de la raza. Un gran certamen de belleza infantil", Mundo Uruguayo, 18 de agosto de 1921.

8. "Las últimas modas del Congo", Mundo Uruguayo, 7 de mayo de 1925.

9. Por ejemplo, en 1921, en el entorno del feriado del 18 de julio se publicaron dos artículos con contenidos históricos: "La fecha histórica del 18 de julio" y "La constitución vigente. Antecedentes históricos”, Mundo Uruguayo, 14 y 21 de julio de 1921.

10. "La conmemoración del primer centenario del desembarco en la Agraciada de los Treinta y Tres Orientales" y "El Centenario del desembarco de los Treinta y Tres Orientales. Cómo se festejó en la histórica playa de la Agraciada", Mundo Uruguayo, 23 de abril de 1925.

11. Carátula correspondiente a la edición de Mundo Uruguayo del 20 de agosto de 1925.

12. La edición especial coincidió con el número 601 de Mundo Uruguayo, publicado el 18 de julio de 1930. A continuación todas las referencias textuales provienen de esta fuente.

\section{RESÚMENES}

En 1925 y 1930 Uruguay conmemoró su primer centenario como país independiente. Ambas fechas coincidieron con la consolidación de un nuevo imaginario nacional que exaltó la excepcionalidad del Uruguay en relación a sus vecinos latinoamericanos.

Esto ocurrió en simultáneo a la introducción de mejoras sustanciales en lo que refiere a la inclusión de fotografías en diarios y revistas. En este artículo se examinan los contenidos gráficos de Mundo Uruguayo -revista destinada a un público masivo, compuesto fundamentalmente por capas medias- procurando identificar el rol desempeñado por las imágenes en este proceso de afianzamiento de un nuevo imaginario hegemónico.

In 1925 and 1930 Uruguay celebrated its first anniversary as an independent country. Both dates coincided with the consolidation of a new national imaginary which was marked by highlighting the exceptionality of Uruguay in relation to its Latin American neighbors. This occurred simultaneously with the introduction of substantial improvements in the inclusion of photographs in newspapers and magazines. This article examines graphics contents of Mundo Uruguayo -magazine for a mass audience, mainly middle class- and seeks to understand the role played by the images on this process of consolidation of a new hegemonic imaginary.

\section{ÍNDICE}

Keywords: press photography, magazines, mundo uruguayo, national imaginary, commemoration of Uruguay's centennial

Palabras claves: fotografía de prensa, revistas ilustradas, mundo uruguayo, imaginario nacional, conmemoración del Centenario 


\section{AUTOR}

\section{MAGDALENA BROQUETAS}

Universisad de la República y Centro de Fotografía de Montevideo

Doctora en Historia por la Universidad Nacional de La Plata (Argentina) y Licenciada en Ciencias Históricas por la Universidad de la República (Uruguay).

Profesora Adjunta en el Departamento de Historia del Uruguay de la Facultad de Humanidades y Ciencias de la Educación (Universidad de la República) y Coordinadora del Área de Investigación del Centro de Fotografía de Montevideo 